\title{
Awareness and Use of Chlorhexidine Gel in Prevention of Neonatal Sepsis among Nurses and Midwives in Selected Health Facilities in Abeokuta, Nigeria
}

\author{
Uririoghene Ikperite, Oluwatosin O. Ope-Babadele", Eunice A. Ojo \\ School of Nursing Sciences, Babcock University, Ogun State, Nigeria
}

\author{
DOI: $10.36348 /$ sjnhc.2020.v03i02.001 \\ | Received: 20.11.2019 | Accepted: 27.11.2019 | Published: 08.02.2020 \\ *Corresponding author: Oluwatosin O. Ope-Babadele
}

\section{Abstract}

Cord infection remains a significant cause of death among neonates in the developing world. Its prevention using the appropriate cleaning agent is key to ensuring the neonates stay free and safe during the period of cord care. This study was conducted to assess the awareness and use of chlorhexidine gel (CHG) in the prevention of neonatal sepsis among nurses and midwives in selected health facilities in Abeokuta. The descriptive study utilized a purposive sampling technique and a questionnaire derived from literature review to collect data from 42 respondents in three selected health facilities in Abeokuta. Findings revealed that while 31\% were aware of the recommendation favoring the use of CHG for cord care, only $10 \%$ understood that the recommended strength for umbilical cord care is the aqueous solution or gel delivering 4\% chlorhexidine. Prevention of umbilical cord infection should center on meticulous care of the umbilical cord with the use of chlorhexidine $(\mathrm{CHG})$ which is the recommended cleaning agent. It is therefore recommended that a seminar or conference should be organized for nurses and midwives as this will increase awareness on the use of chlorhexidine gel for umbilical cord care and its benefits.

Keywords: Awareness, Use, Chlorhexidine gel, Prevention, neonatal sepsis, Nurses, Midwives.

Copyright @ 2020: This is an open-access article distributed under the terms of the Creative Commons Attribution license which permits unrestricted use, distribution, and reproduction in any medium for non-commercial use (NonCommercial, or CC-BY-NC) provided the original author and source are credited.

\section{INTRODUCTION}

A child's first few days of life present the highest risks to his or her survival [1]. Given that the child, on his/her own, is defenseless, the parents/guardians have an unflinching responsibility of ensuring that they are committed to recommended essential newborn care practices, with a penchant for details against the child's various susceptibilities, one of which is the very dreaded neonatal sepsis [2].

Neonatal sepsis is defined as a clinical syndrome in an infant 28 days of life or younger, manifested by systemic signs of infection and isolation of a bacterial pathogen from the bloodstream. It accounts for $36 \%$ of the total annual 3.3 million neonatal deaths recorded globally [3], and probably responsible for a Neonatal Mortality Rate (NMR) of 34.1 per 1000 live births in Nigeria in 2016, which was about the highest in the West African sub-region in 2006 [3].

Although the neonates' frailty provides many routes for infection, [4] submitted that the umbilical cord is the most common portal of entry for pathogenic microbes. As a result, neonatal sepsis most often erupts from local cord infections, known as omphalitis [3].

Globally, neonatal tetanus, accounts for $7 \%$ of neonatal deaths, but accounts for more than $33 \%$ in Nigeria, which is one of the 27 countries that bear $90 \%$ of the global burden of the disease [5]

As seemingly invincible as neonatal sepsis is, reducing its prevalence is not impossible. It is in the realization of it that the World Health Organization in 2013 issued a statement admonishing that in places where the incidence of neonatal mortality is greater than 30 per 1000 live births, a salt of $7.1 \%$ chlorhexidine, chlorhexidine digluconate (aqueous solution or gel delivering $4 \%$ chlorhexidine) ( $\mathrm{CHG}$ ), should be daily applied to the umbilical stump during the neonatal period. Having recorded evidences of the effectiveness of chlorhexidine-based solution, the WHO recommendations came on the realization that, if the umbilical cord can be safeguarded from pathogens, the incidence of neonatal sepsis or mortality will reduce drastically. 
Ultimately, Nigeria, whose neonatal mortality ratio (NMR) is far above 30 per 1000 live births, is among the countries for which chlorhexidine use is recommended. Unfortunately, despite the effectiveness of $\mathrm{CHG}$ and its recommendation for low-resource settings [6], reported a less than $10 \%$ use of $\mathrm{CHG}$ in cord care. Instead, other substances, such as methylated spirit, are reportedly popular among midwives.

It follows then that the key to improving compliance with CHG for cord care in Abeokuta lies hugely in the testimonies of nurses and midwives in the region. However, whether or not the nurses and midwives in Abeokuta South Local Government accept CHG for umbilical cord cleaning is still uncertain. As a necessary step to promoting compliance, this study therefore seeks to assess the acceptance and use of CHG in umbilical cord care among nurses and midwives in selected health facilities in Abeokuta.

\section{METHOD}

Design: A descriptive cross-sectional survey design was used.

\section{Sample and Setting}

A purposive sampling technique was used. Nurses working in 3 selected health facilities (1 federal, 1 state hospital and 1 local health facility) were recruited using total enumeration sampling technique. These hospitals have the highest population of nurses and client flow as compared to other hospitals in Abeokuta city.

\section{Data Collection}

Two trained research assistants collected data. All nurses working in the targeted units of the selected hospitals were approached to participate in the study. The researcher visited the different hospitals to explain the purpose of the study and to invite nurses to voluntarily participate. Upon agreeing to participate, they were asked to read and sign the consent form and then complete the questionnaire. Due to the busy schedule and job task of nurses, the morning and afternoon shifts were employed in data collection. Some nurses were assessed during their break period, some filled the questionnaire on the spot and returned it immediately while some were collected by the nurses and retrieved later. A total of 42 nurses completed the questionnaire with a response rate of $80 \%$. All completed questionnaires were valid for use.

\section{Data Analysis}

The demographic data including age, sex, years of experience and professional qualification were analyzed using descriptive statistics. In addition, Statistical Package for Social Sciences (SPSS) version 23 was used to analyze the data collected.

\section{Ethical Considerations}

Ethical approval was obtained from the researcher's institution and from the Research Ethics committee of all the health facilities used. Confidentiality was maintained throughout the study. Participants' anonymity was ensured by not asking the participants to write any identifying information on the questionnaire. There was no potential risk to participation and nurses were informed that they could quit at any time in case they preferred not to complete the questionnaire.

\section{RESULTS}

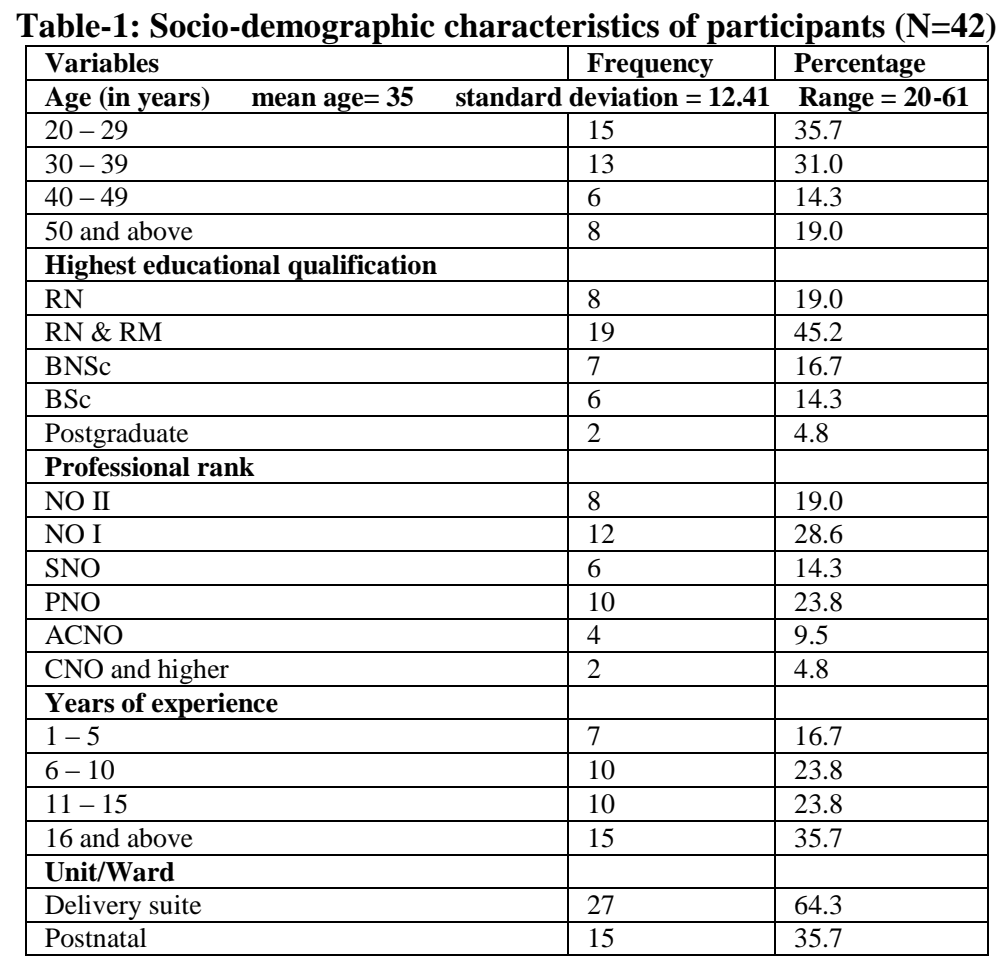


Of the 52 nurses who participated in the study, a total of 42 completed the questionnaire. A larger proportion of the sample population are within the age range of 20-29 years (35.7\%), have $\mathrm{RN}$ and $\mathrm{RM}$ qualification (45.2\%), are NO I (28.6\%), have had 16 years of experience $(35.7 \%)$ and are currently working in the delivery suite $(64.3 \%)$.

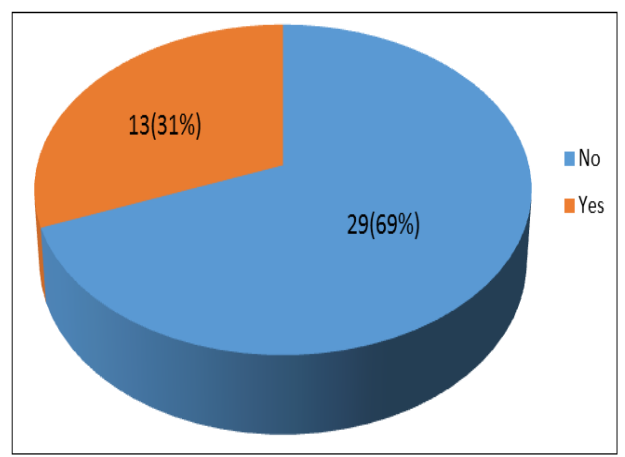

Fig-1: Awareness of Nurses on the Recommendations of CHG in umbilical cord care
The pie chart showed if respondents are aware of the guidelines recommending chlorhexidine gel for cord care. It was deduced that 29(69\%) respondents were not aware of any guideline recommendations and hence, do not know about the recommended strength. Out of the approximately $31 \%$ who consented to being aware of the recommendations, only $2(5 \%)$ of them actually know the recommended strength for administration.

This finding implies that the majority of hospitals/health institutions have not adopted nor enforced any policy on the use of chlorhexidine for umbilical cord care among health care workers especially nurses and midwives. This finding is in line with the study of [7] where result showed that only a few had a good knowledge of its recommendation as a preferred cleaning agent in cord care.

Table-2: Substances used by respondents for umbilical cord care $(\mathrm{N}=42)$

\begin{tabular}{|l|l|l|l|l|}
\hline Items & Always & Sometimes & Rarely & Never \\
\hline Methylated spirit & $19(45.2)$ & $14(33.3)$ & $4(9.5)$ & $5(11.9)$ \\
\hline $\begin{array}{l}\text { Chlorhexidine digluconeate (or chlorhexidine-based } \\
\text { gel/solution) }\end{array}$ & $8(19.0)$ & $10(23.8)$ & $17(40.5)$ & $7(16.7)$ \\
\hline Normal saline & $4(9.5)$ & $9(21.4)$ & $16(38.1)$ & $13(31.0)$ \\
\hline Other substances: providone, iodine, antibacterial cream & $8(19.0)$ & $15(35.7)$ & $12(28.6)$ & $7(16.7)$ \\
\hline
\end{tabular}

The table above shows the different substances that nurses use for umbilical cord care. Methylated spirit is the most commonly used substance for the care of the umbilicus with $19(45.2 \%)$ indicating that they use it always while $14(33.3 \%)$ use it sometimes. Chlorhexidine digluconeate and other substances like providone, iodine or antibacterial cream are used always by only a few of the respondents. While $10(23.8 \%)$ respondents use chlorhexidine digluconeate sometimes, $15(35.7 \%)$ do so with other substances. The least substance that was used by respondents was normal saline. Though majority $16(38.1 \%)$ use it rarely, $13(31 \%)$ of respondents said they have never used it which is higher than those of other substances.

This finding is found to be in tandem with the study of [6] whose study assessed the knowledge and practice of immediate newborn care among health care providers in Ethiopia. The study reported that though over $70 \%$ of the health workers have adequate newborn care practice, only a small percentage of participants apply chlorhexidine to cord after cord cutting.

From the researchers' point of view, this implies that the health facilities and her workers especially those involved in newborn care including nurses and midwives are yet to come to terms with the recommendation of WHO on the use of Chlorhexidine. It may also be due to a lack of communication and information on new trends evolving in the health care environment.

The implication of this study to nursing is the fact that nurses are not using recommended guidelines and available evidence to inform practice. It is therefore important that nurse leaders drive the initiative and ensure that WHO recommendations on the use of chlorhexidine gluconeate for umbilical cord care be adhered to. Conferences and seminars should be organized for midwives working in antenatal, delivery suite and post natal clinics in order to provide up-todate and first-hand information on the efficacy and benefits of this gel based on evidence from research. This will in no small measure create awareness, improve knowledge and correct poor perception of chlorhexidine gel among nurses.

In view of the findings of this study, the following recommendations would suffice:

A seminar or conference should be organized for nurse midwives in the state that will create increasing awareness of the use of chlorhexidine gel for umbilical cord care and its benefits.

Awareness should be created to the general public on the benefits of use of chlorhexidine gluconeate for cord care through media like television, radio, and visual aids in hospitals. 
Nurse midwives should educate pregnant women on the use and benefits of chlorhexidine gel during antenatal visits in order to promote its acceptance among mothers.

Government through the ministry of health should put in place policies that will ensure the scale up of the use of chlorhexidine gluconeate for use in umbilical cord care and its use should be enforced with appropriate laws and supervision.

Government should ensure that chlorhexidine gel is readily available and affordable in the country especially to rural underserved communities by ensuring all year round supply and subsidizing its price where necessary.

For further study, a quasi-experimental study should be carried out to examine the effect of use of chlorhexidine gel for umbilical cord care on neonatal health outcome.

\section{CONCLUSION}

Findings from this study have shown that majority are not aware of guidelines recommending chlorhexidine while minority are aware. Methylated spirit is the most commonly used substance for the care of the umbilicus with majority indicating that they use it always while minority use it sometimes. Chlorhexidine digluconeate and other substances like providone-iodine or antibacterial cream are used always by least respondents respectively. Specifically, in the past four weeks, majority indicated they have never used chlorhexidine gluconeate, some use it sometimes while only minority use it always.

\section{REFERENCES}

1. Amolo, L. (2014). Knowledge and attitude of postnatal mothers on essential newborn care practices at kenyatta national hospital (Doctoral dissertation, University of Nairobi).

2. Gathwala, G., Sharma, D., \& Bhakhri, B. K. (2013). Effect of topical application of chlorhexidine for umbilical cord care in comparison with conventional dry cord care on the risk of neonatal sepsis: a randomized controlled trial. Journal of tropical pediatrics, 59(3), 209213.

3. Nutor, J. J., Kayingo, G., Bell, J. F., \& Joseph, J. G. (2016). Knowledge, attitudes and practices regarding care of newborn umbilical cord among healthcare workers and mothers in the Volta region of Ghana. Annals of Global Health, 82(3), 548.

4. Bhatt, B., Malik, J. S., Jindal, H., Sahoo, S., \& Sangwan, K. (2015). A study to assess cord care practices among mothers of new borns in urban areas of Rohtak Haryana. Int J Basic Appl Med Sci, 5(1), 55-60.

5. Peter, O., \& Johnson, J. (2010). Risk Factors for Neonatal Infections. Global Journal, 12:40-46.

6. Berhe, A. K., Tinsae, F., \& Gebreegziabher, G. (2017). Knowledge and practice of immediate newborn care among health care providers in eastern zone public health facilities, Tigray, Ethiopia, 2016. BMC pediatrics, 17(1), 157.

7. Obaid, K., Hussein, A., \& Noori, A. (2016). Nurses knowledge concerning neonatal sepsis in neonatal intensive care units at pediatric teaching hospitals in Baghdad City. Retrieved 6th March, 2018 from https://www.researchgate.net/profile/Khamees_Ob aid. 